\title{
Discovery of KIRREL as a biomarker for prognostic stratification of patients with thin melanoma
}

\author{
Sebastian Lundgren', Helena Fagerström-Vahman', Cheng Zhang², Liv Ben-Dror', Adil Mardinoglu², \\ Mathias Uhlen², Björn Nodin ${ }^{1}$ and Karin Jirström ${ }^{1 *}$ (D)
}

\begin{abstract}
There is a great unmet clinical need to identify patients with thin primary cutaneous melanomas (T1, Breslow thickness $\leq 1 \mathrm{~mm}$ ) who have a high risk for tumour recurrence and death from melanoma. Kin of IRRE-like protein 1 (KIRREL/NEPH1) is expressed in podocytes and involved in glomerular filtration. Screening in the Human Protein Atlas portal revealed a particularly high expression of KIRREL in melanoma, both at the mRNA and protein levels. In this study, we followed up on these findings and examined the prognostic value of KIRREL in a population-based cohort.

Immunohistochemical expression of KIRREL was examined in tissue microarrays with a subset of primary tumours and paired lymph node metastases from an original cohort of 268 incident cases of melanoma in the Malmö Diet and Cancer study. KIRREL mRNA expression was examined in 103 melanoma cases in The Cancer Genome Atlas (TCGA).

Membranous/cytoplasmic expression of KIRREL was detected in 158/185 (85.4\%) primary tumours and 18/19 (94.7\%) metastases. High expression of KIRREL was significantly associated with several unfavourable

clinicopathological factors.

High KIRREL protein expression was an independent factor of reduced recurrence free and melanoma specific survival, particularly in thin melanomas, even outperforming absolute thickness and ulceration $(H R=30.85 ; 95 \%$ $\mathrm{Cl} 1.54-616.36$ and $\mathrm{HR}=6.3295 \% \mathrm{Cl} 1.19-33.65)$. High mRNA levels of KIRREL were not significantly associated with survival in TCGA.

In conclusion, KIRREL is not only a novel potential diagnostic marker for melanoma, but may also be a useful prognostic biomarker for improved stratification of patients with thin melanoma. These findings may be of high clinical relevance and therefore merit further validation.
\end{abstract}

Keywords: Melanoma, KIRREL, NEPH1, Prognosis

Cutaneous melanoma is the most aggressive and deadliest form of skin cancer with a rising incidence globally [1]. Kin of IRRE protein (KIRREL) is a member of a podocin binding protein family, which primary physiological role is in the renal glomeruli where it safeguards selective ultrafiltration [2]. As of yet, research regarding the expression and role of KIRREL in cancer has been sparse. A recent study demonstrated that high expression

\footnotetext{
* Correspondence: karin.jirstrom@med.lu.se

'Department of Clinical Sciences Lund, Oncology and Pathology, Lund University, Lund, Sweden

Full list of author information is available at the end of the article
}

of KIRREL is associated with unfavorable clinicopathological factors and poor prognosis in gastric cancer [3], and KIRREL has also been implicated in the carcinogenesis of pancreatic cancer [4]. We conducted a screening of mRNA and protein levels of KIRREL across several cancers and normal tissues in the Human Protein Atlas (HPA) portal (www.proteinatlas.org) [5], which revealed a particularly high expression in melanoma. The aim of this study was therefore to further investigate the expression, clinicopathological correlates and prognostic impact of KIRREL in melanoma, both at the protein and mRNA levels. 


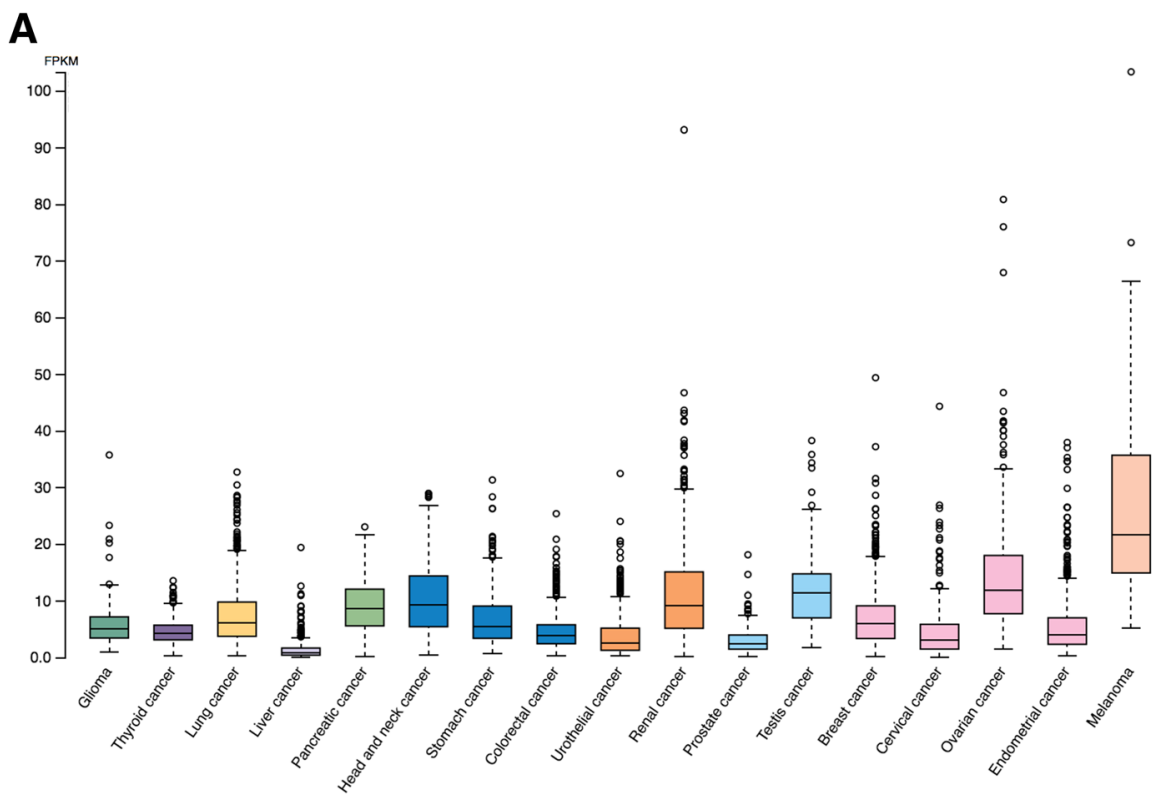

B

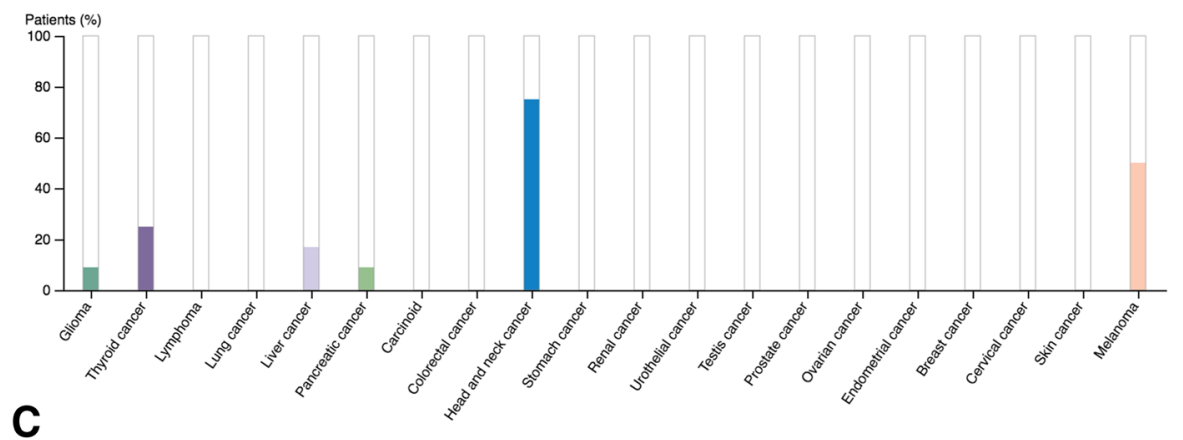

C
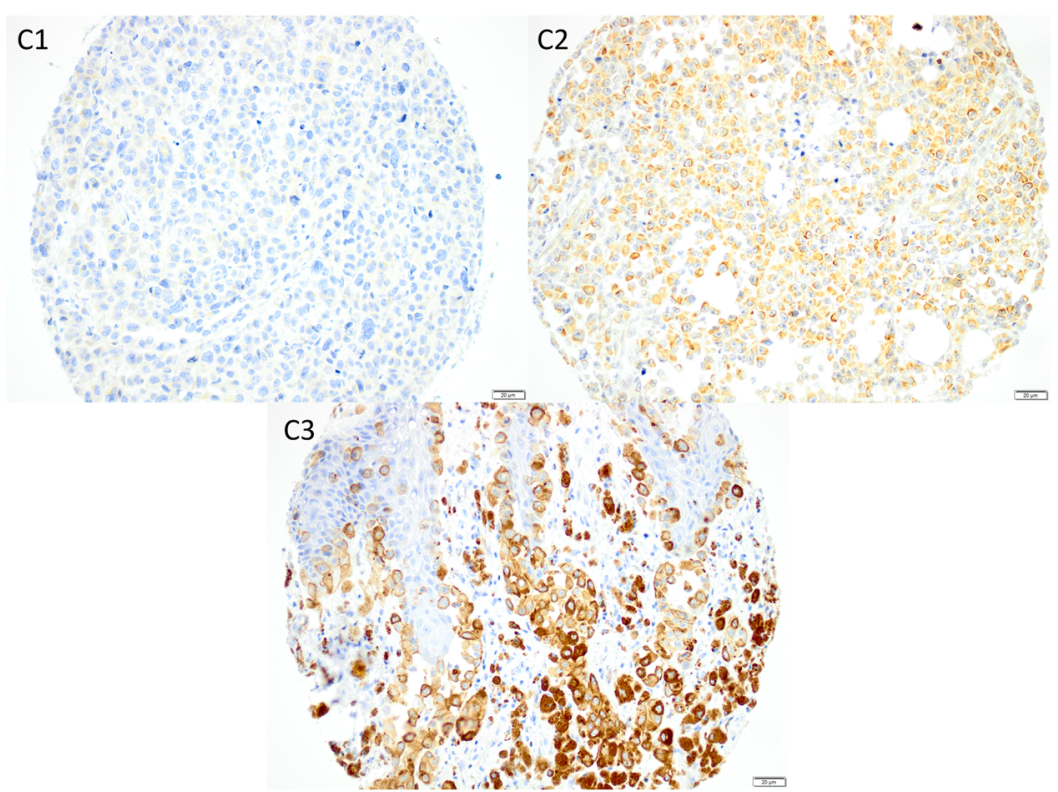

Fig. 1 (See legend on next page.) 
(See figure on previous page.)

Fig. 1 Overview of KIRREL expression at the mRNA and protein levels in different cancer types and sample images of immunohistochemical staining in melanoma. a KIRREL mRNA expression overview and (b) KIRREL protein expression summary across several cancer types. c Immunohistochemical images from melanoma cases in the Malmö Diet and Cancer study, exemplifying tumors with 1) negative, 2) intermediate, and 3) high expression

\section{Results and discussion}

mRNA and protein expression of KIRREL in various types of cancers in the HPA are shown in Fig. 1 a, b. KIRREL expression was further examined by immunohistochemical analysis of 226 cases of incident melanoma in the population-based cohort Malmö Diet and Cancer study, from which tissue microarrays had been constructed as previously described (Additional file 1) [6].

Sample immunohistochemical images of KIRREL staining are shown in Fig. 1c. Digital images of KIRREL expression in 12 cases of melanoma are also shown in the HPA: https://www.proteinatlas.org/ENSG00000183853-KIR-

REL/pathology/tissue/melanoma.

Membranous and cytoplasmic KIRREL expression was detected in 158/185 (85.4\%) of evaluable primary tumours and in 18/19 (94.7\%) of evaluable metastases. Pairwise comparisons between mean expression of KIRREL in primary tumours and metastases revealed a higher expression in the latter, however this difference was not significant $(p=0.17)$.

The associations of KIRREL expression with clinicopathological factors are detailed in Additional file 2, and significant associations are visualized in Fig. 2. High expression of KIRREL was significantly associated with several unfavourable clinicopathological traits, including high Clark level and Breslow stage, ulceration, clinical stage, and high mitotic count. These findings are in line with a recent study on gastric cancer that demonstrated that KIRREL expression is associated with several adverse clinicopathological factors [3, 7].

Next we examined the impact of immunohistochemical KIRREL expression on patient outcome. After a median follow-up of 11.8 years (range 0.624.8), $113(50 \%)$ of patients had died, $36(31.8 \%)$ of whom from melanoma, and recurrent disease was denoted in 50 (22.1\%) cases. As shown in Fig. 3, high KIRREL expression was a significantly associated with reduced melanoma-specific survival (MSS) $(p=0.017)$, and a trend, however non-significant, towards a shorter recurrence free survival (RFS) $(p=0.071)$. These associations were confirmed in univariable Cox regression analysis (Hazard ratio $[\mathrm{HR}]=1.69$ 95\% Confidence interval [CI] 0.95-2.99 and $\mathrm{HR}=2.2395 \%$ CI 1.13-4.00, respectively), but did not remain significant in multivariable analysis (data not shown).

In thin melanomas (Breslow thickness $\leq 1 \mathrm{~mm}$ ) high protein expression of KIRREL was significantly associated with both poor RFS and reduced MSS $(p=0.004$ and $p=0.007$, respectively) (Fig. 3). As shown in Additional file 3, these associations were confirmed in univariable Cox regression analysis and remained significant in multivariable analysis $(\mathrm{HR}=30.8 ; 95 \% \mathrm{CI}$ 1.34-616, HR $=6.32$ 95\% CI1.19-33.65 respectively), even outperforming well-established prognostic factors such as absolute thickness in millimetre and presence of ulceration.

Thin melanomas already make up $70 \%$ of all newly diagnosed melanomas [8], a number that may increase due to efforts for earlier diagnosis, and although they can collectively be regarded as having a good prognosis, some tumours will metastasize and lead to death. Current clinical protocols still lack reliable biomarkers for stratification of patients with thin melanoma having high or low risk for recurrence, and the findings in this paper indicate that KIRREL might valuable in this regard.

In order to validate the findings at the protein level, data on mRNA expression of KIRREL was retrieved from 103 melanoma cases in TCGA. As only two cases had matched samples from the primary tumour and metastasis, no meaningful comparison could be performed. There was no significant association between KIRREL expression and clinical stage (data not shown) and information on other clinicopathological factors was not available.

KIRREL expression was not prognostic at the mRNA level (Additional file 4), and as only 3 cases were stage I, no subgroup analysis could be carried out for thin melanoma.

\section{Conclusions}

This is the first study to describe the expression of KIRREL at the protein and mRNA levels in cutaneous melanoma. The results demonstrate a particularly high expression of KIRREL in melanoma compared to other types of solid cancer, in both primary tumours and metastases, hence highlighting its potential as a novel diagnostic adjunct. Moreover, KIRREL may also prove to be a useful biomarker for improved prognostic stratification of thin melanoma, an entity for which there is great unmet need for improved risk stratification. Further research into the role of KIRREL in the pathogenesis and progression of melanoma, and validatory studies regarding its clinical impact, are warranted. 

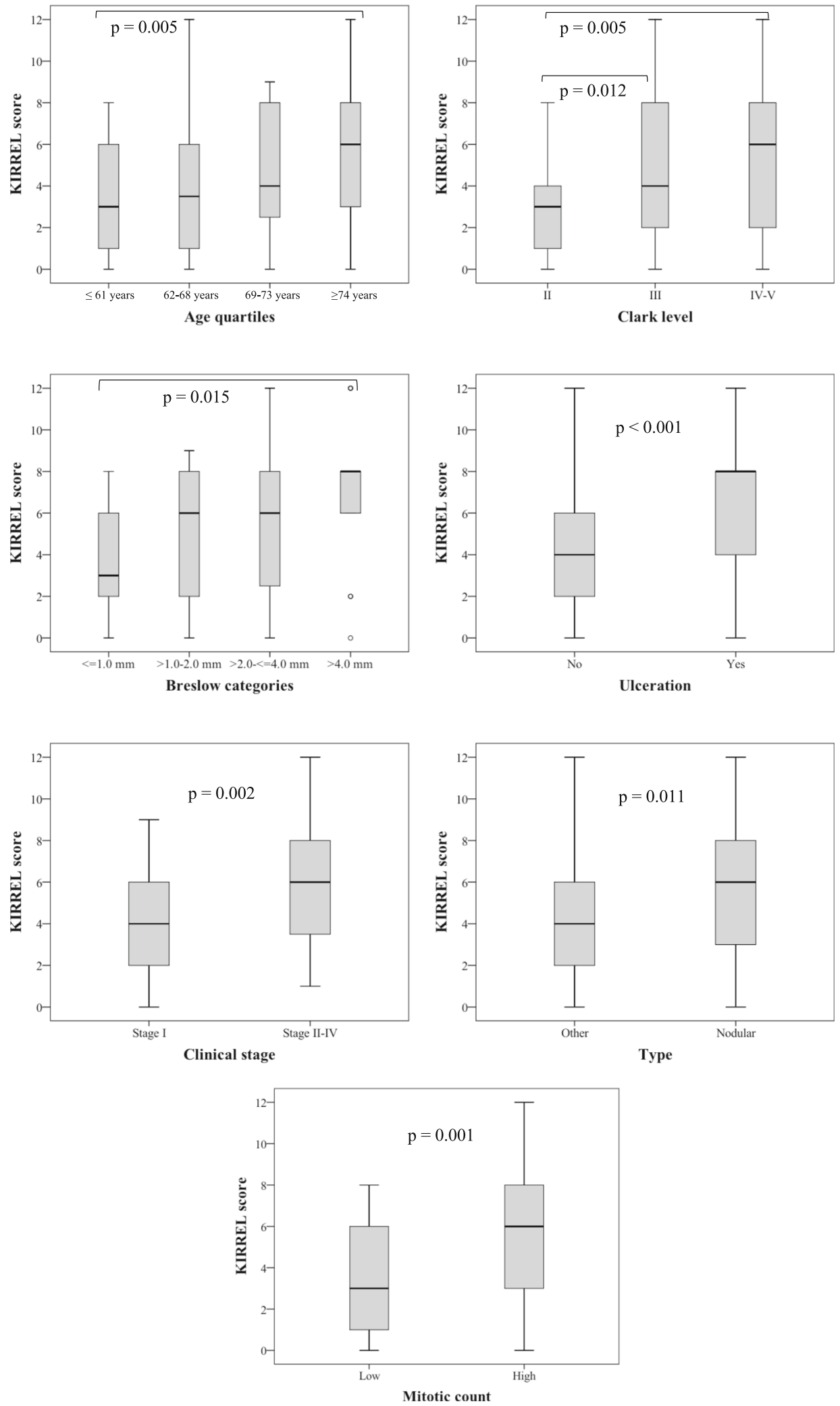

Fig. 2 Distribution of KIRREL expression in relation to clinicopathological factors. Box plots visualizing the distribution of the full KIRREL score in relation to clinicopathological factors. Only significant $p$-values are shown. Error bars indicate $95 \%$ confidence interval 

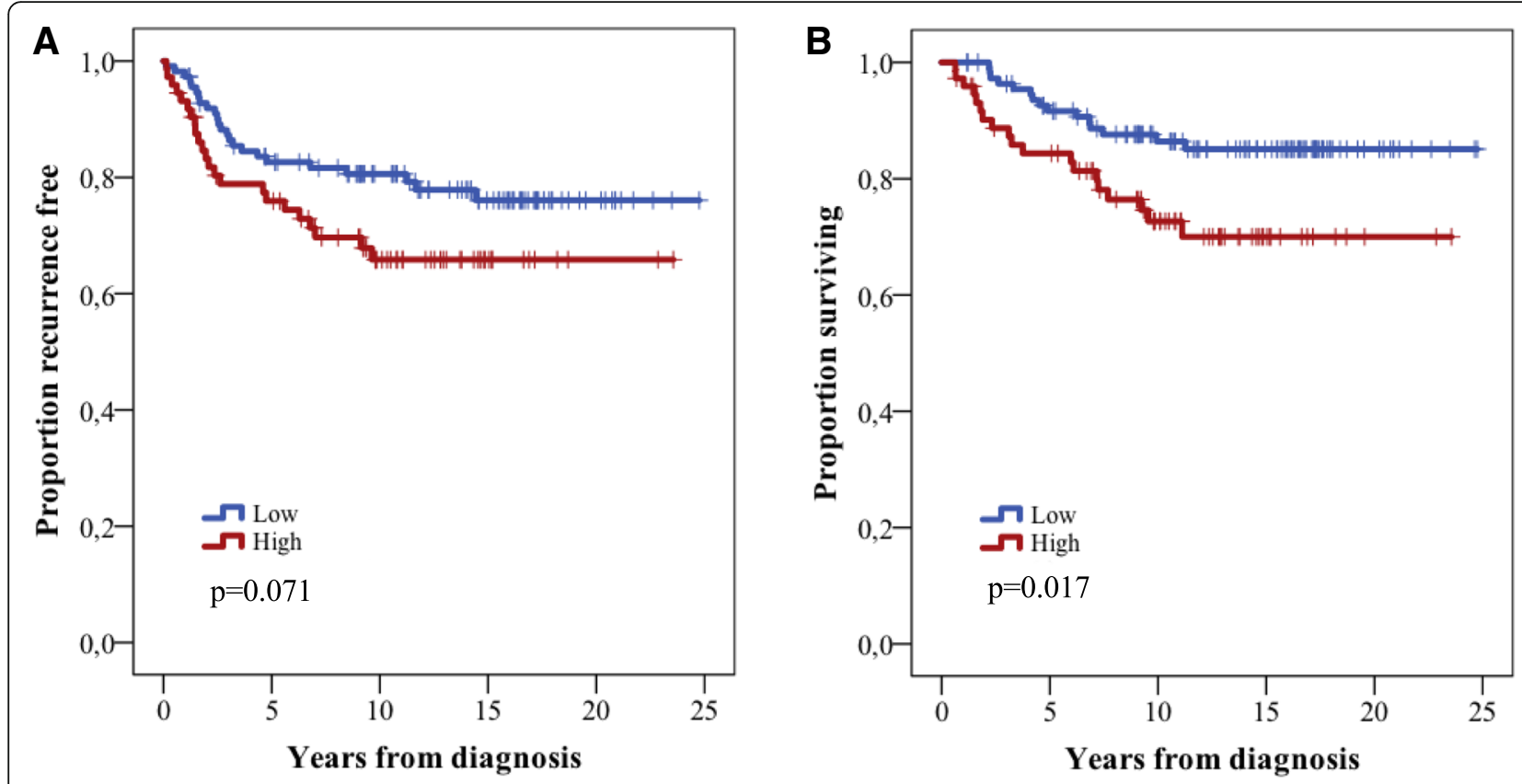

Number at risk

$\begin{array}{llllll}\text { Low } & 112 & 87 & 66 & 39 & 10 \\ \text { High } & 73 & 52 & 30 & 10 & 2\end{array}$

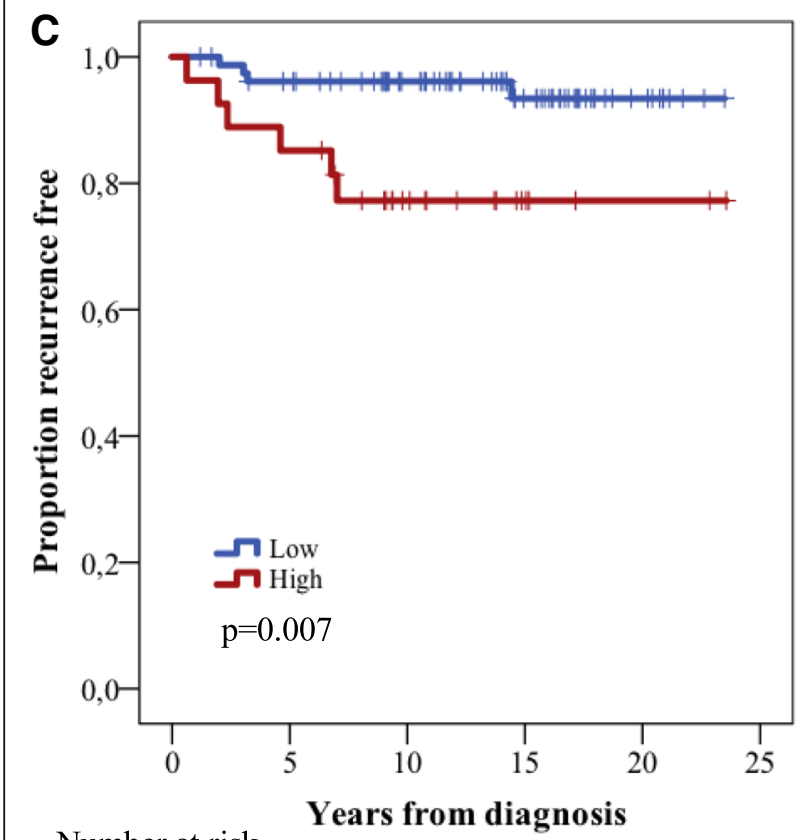

Number at risk

$\begin{array}{llllll}\text { Low } & 112 & 96 & 71 & 46 & 11 \\ \text { High } & 73 & 58 & 35 & 12 & 2\end{array}$

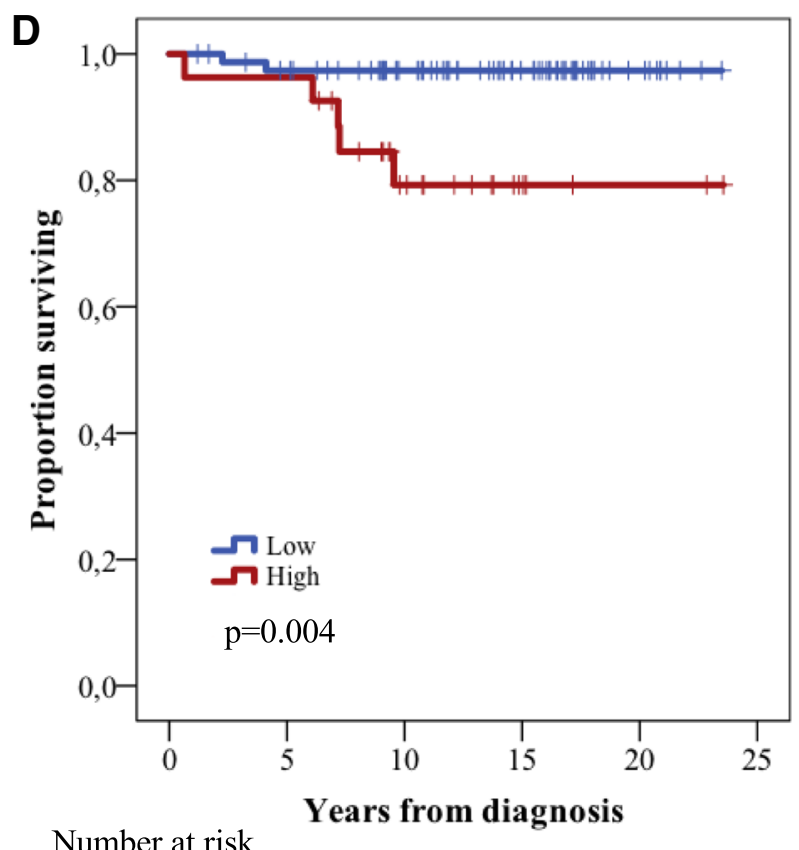

Number at risk

$\begin{array}{llllll}\text { Low } & 79 & 52 & 55 & 32 & 9 \\ \text { High } & 27 & 23 & 13 & 5 & 2\end{array}$

Number at risk

$\begin{array}{llllll}\text { Low } & 79 & 73 & 56 & 34 & 9 \\ \text { High } & 27 & 26 & 14 & 5 & 2\end{array}$

Fig. 3 Kaplan-Meier estimates illustrating differences in clinical outcome stratified by KIRREL expression. a Recurrence free survival in the entire cohort. b Melanoma specific survival in the entire cohort. c Recurrence free survival in thin melanomas only. d Melanoma specific survival in thin melanomas only 


\section{Additional files}

Additional file 1: Materials and Methods. (DOCX $19 \mathrm{~kb}$ )

Additional file 2: Associations of KIRREL protein expression with clinicopathological factors in the entire cohort. (DOCX $22 \mathrm{~kb}$ )

Additional file 3: Cox regression analysis of hazard ratios for $A$ ) recurrence and B) death from melanoma in thin melanoma. (DOCX $23 \mathrm{~kb}$ )

Additional file 4: Kaplan-Meier curve illustrating overall survival according to high and low mRNA expression (median cutoff) in TCGA dataset. (PDF $45 \mathrm{~kb}$ )

\section{Abbreviations}

Cl: Confidence interval; FPKM: Fragments Per Kilobase Million; HPA: Human Protein Atlas; HR: Hazard ratio; KIRREL: Kin of IRRE like; MSS: Melanoma specific survival; RFS: Recurrence free survival; TCGA: The Cancer Genome Atlas

\section{Acknowledgments}

Not applicable.

\section{Funding}

This work was supported by grants from The Swedish Research Council, the Mrs. Berta Kamprad Foundation, Governmental Funding of Clinical Research within the National Health Service (ALF), Lund University Faculty of Medicine and Skåne University Hospital Funds and Donations.

\section{Availability of data and materials}

All data generated or analysed during this study are included in this published article.

\section{Authors' contributions}

Conceived and designed the experiments: KJ. Performed the experiments: HFV, KJ. Analysed the data: SL, KJ, CZ, AM. Contributed reagents/materials/ analysis tools: BN, MU. Wrote the paper: SL, KJ. All authors have read and approved the final manuscript.

\section{Ethics approval and consent to participate}

All national and European Union regulations and requirements for handling human samples have been fully complied with during the conduct of this study; i.e. decision no. 1110/94/EC of the European Parliament and of the Council (OJL126 18,5,94), the Helsinki Declaration on ethical principles for medical research involving human subjects, and the European Union Council Convention on human rights and Biomedicine. Approval for the study was obtained from the Ethics committee of Lund University (reference number 530/2008 and 445/07), whereby the committee waived no need for consent other than the option to opt out.

\section{Consent for publication}

Not applicable.

\section{Competing interests}

The authors declare that they have no competing interests.

\section{Publisher's Note}

Springer Nature remains neutral with regard to jurisdictional claims in published maps and institutional affiliations.

\section{Author details}

'Department of Clinical Sciences Lund, Oncology and Pathology, Lund University, Lund, Sweden. ${ }^{2}$ Science for Life Laboratory, Department of Proteomics, School of Biotechnology, Royal Institute of Technology, Stockholm, Sweden.

Received: 5 November 2018 Accepted: 28 December 2018 Published online: 14 January 2019

\section{References}

1. Dimitriou F, Krattinger R, Ramelyte E, Barysch MJ, Micaletto S, Dummer R, Goldinger SM. The world of melanoma: epidemiologic, genetic, and anatomic differences of melanoma across the globe. Curr Oncol Rep. 2018; 20(11):87.

2. Sellin L, Huber TB, Gerke P, Quack I, Pavenstadt H, Walz G. NEPH1 defines a novel family of podocin interacting proteins. FASEB J. 2003;17(1):115-7.

3. Zhang MJ, Hong YY, Li N. Overexpression of kin of IRRE-like protein 1 (KIRREL) in gastric Cancer and its clinical prognostic significance. Med Sci Monit. 2018;24:2711-9.

4. Hu B, Shi C, Jiang HX, Qin SY. Identification of novel therapeutic target genes and pathway in pancreatic cancer by integrative analysis. Medicine. 2017;96(42):e8261.

5. Uhlen M, Zhang C, Lee S, Sjostedt E, Fagerberg L, Bidkhori G, Benfeitas R, Arif M, Liu Z, Edfors F, et al. A pathology atlas of the human cancer transcriptome. Science (New York, NY). 2017:357(6352).

6. Jonsson L, Bergman J, Nodin B, Manjer J, Ponten F, Uhlen M, Jirstrom K. Low RBM3 protein expression correlates with tumour progression and poor prognosis in malignant melanoma: an analysis of 215 cases from the Malmo diet and Cancer study. J Transl Med. 2011;9:114.

7. Chen J, Wang X, Hu B, He Y, Qian X, Wang W. Candidate genes in gastric cancer identified by constructing a weighted gene co-expression network. PeerJ. 2018:6:e4692.

8. Geller AC, Clapp RW, Sober AJ, Gonsalves L, Mueller L, Christiansen CL, Shaikh W, Miller DR. Melanoma epidemic: an analysis of six decades of data from the Connecticut tumor registry. J Clin Oncol. 2013;31(33):4172-8.

\section{Ready to submit your research? Choose BMC and benefit from:}

- fast, convenient online submission

- thorough peer review by experienced researchers in your field

- rapid publication on acceptance

- support for research data, including large and complex data types

- gold Open Access which fosters wider collaboration and increased citations

- maximum visibility for your research: over $100 \mathrm{M}$ website views per year

At $\mathrm{BMC}$, research is always in progress.

Learn more biomedcentral.com/submissions 